\title{
Acute urticaria in children: what can we learn from clinical practice?
}

\author{
Nataliya Banadyha ${ }^{1}$ and Alla Nakonechna ${ }^{2}$ \\ ${ }^{1}$ Horbachevsky Ternopil State Medical University \\ ${ }^{2}$ University of Liverpool
}

March 31, 2021

\begin{abstract}
Acute urticaria in children: what can we learn from clinical practice?
\end{abstract}

\section{DR Nataliya Banadyha ( Orchid ID: 0000-0001-7930-184X)}

\section{Acute urticaria in children: what can we learn from clinical practice?}

\section{To the Editor,}

Acute urticaria $(\mathrm{AU})$ in children is a common pathology for primary care physicians ${ }^{1,2,3}$. However, there are difficulties in diagnosis, indications for hospitalization, amount and composition of emergency therapy. Moreover, there are lack of published data on the duration, the severity, co-existed angioedema, response to treatment, rate of becoming chronic and how they link to the different causes in childhood AU. Analysis of existing guidelines ${ }^{4,5,6}$, lack of National consensus on $\mathrm{AU}$, arouse interest in the awareness of pediatricians on the issues of diagnosis and rational treatment approaches.

We therefore performed a retrospective analysis on 74 children treated in the pediatric wards of the Ternopil City Children's Hospital with a diagnosis of AU in 2018-2020. Boys predominated in $58.1 \%$ among patients (43 of 74). The age structure of the surveyed was represented by: 32 children (43.2\%) of the first three years of life and of them 15 (46. 9\%) of the first year; 14 (18.9\%) preschoolers, 28 (37.9\%) schoolchildren.

Attention was drawn to the concern of parents who in the first hours after the appearance of urticaria in a child sought emergency medical team (48.7\%) or immediately attended to the emergency department (17.6\%) and all of them were hospitalized; while other $33.7 \%$ who had acute respiratory infections and urticaria were referred for hospitalization by family doctors on 2-3rd days (table 1). Among all examined there were two groups of patients: $40(54 \%)$ had skin symptoms (urticaria, angioedema, itching, redness) without obvious cause and $34(46 \%)$ initially developed acute respiratory viral infection, followed by urticaria. It is noteworthy that with the typical symptoms of urticaria, the diagnoses varied as: urticaria (42.3\%), allergic reaction $(34.6 \%)$, atopic dermatitis $(1.9 \%)$, food allergy $(1.9 \%)$, bee / wasp stings $(3.8 \%)$, acute respiratory viral infection along with urticarial $(13.5 \%)$.

In the vast majority of cases $(66.2 \%)$, the urticarial rash appeared for the first time in life. $31.1 \%$ of patients had a history of allergy, mostly to food, insect, medications. Among triggers of AU certain foods was found in $12.2 \%$, insect in $8.1 \%$, non-steroidal anti-inflammatory drugs or antibiotics in $12.2 \%$; while in $21.6 \% \mathrm{AU}$ was idiopathic. 
Our findings support the results of other scientific studies, that point to the special role of infections in childhood $\mathrm{AU}^{2,7,8}$, particularly herpes viruses, cytomegalovirus, Epstein-Barr, enterovirus, hepatitis B, C.

It is disputable whether hospitalization in children with acute urticaria was justified? Under these circumstances, the severity of children's urticaria and associated anxiety of parents should be considered. The localization of urticarial rash in all observed children was mostly common throughout the body and in only $13.5 \%$ of cases was limited to face or scalp. In only one in four children urticaria was accompanied by angioedema, and of them in a third $(31.6 \%)$ was localized on eyelids, lips, face. One child had throat angioedema, affecting breathing. In terms of age, angioedema was more common in schoolchildren (42.1\%) and children in the first two years of life $(36.8 \%$ ). Analyses of symptoms duration (table 1) showed that during the first or second day, urticaria disappeared in $56.8 \%$ and angioedema in $68.4 \%$ of children. This fact needs to be clearly defined in the indications for hospitalization of children with AU. That will reduce the frequency of unreasonable use of hospital resources.

The emergency treatment was provided to 36 patients.. Of them corticosteroids were given to 29 (80.6\%) (dexamethasone - $75.9 \%$, prednisolone - 20.7\%), as a first line of treatment. Additionally, 11 patients (37.9\%) were administered the first-generation antihistamines. Of 34 children with acute respiratory infections and urticaria $67.6 \%$ were given first generation antihistamines, $56.8 \%$ - corticosteroids, $37.8 \%$ - second generation antihistamines.

The dynamics traced the duration of skin rashes at $2.9 \pm 2.3$ days, while angioedema additionally lasted 1.7 \pm 1.4 more days. In 5 patients $(6.8 \%)$ there was a complete regression of symptoms after using only standard dose of oral first-generation antihistamines. Meanwhile 21 children (28.4\%) experienced recurrent episodes of rash with no effect from oral antihistamines. Of them 16 (76.2\%) underwent additionally corticosteroids, $12(57.1 \%)$ second-generation antihistamines and 4 (19.1\%) first-generation antihistamines im/iv.

The main strengths of our study include the data on the duration of urticaria and angioedema symptoms, the severity of symptoms, influence of co-existed angioedema and response to treatment in children with AU. Our findings showed a high frequency of hospitalization in children with acute urticaria and treatment of parents for help in emergency department.

Given that there are differences in the management of $\mathrm{AU}$ with existing guidelines ${ }^{4,5,6}$, we think that some emphasis should be made. The clinical implementation raised the fact that is crucial to indicate the symptoms for hospitalization in children with AU, involving other organ systems beyond the skin, such as the pulmonary (wheezing, stridor), cardiovascular (tachycardia, hypotension, collapse), gastrointestinal (diarrhoea, vomiting, abdominal pain) or nervous system (dizziness, loss of consciousness).

The importance of adequate management and treatment of AU should be noted. In accordance with the existing experience in the world, the advantages in the first line treatment are given to second-generation antihistamines; in the absence of effect, the dose should be doubled. At the same time, there are caveats to their use in pediatrics: most are allowed in children older than two years; however, individual molecules are allowed from six months (levocetirizine) or from one year of age under medical supervision (cetirizine $)^{9,10}$; in the USA cetirizine licensed for children aged over 6 months ${ }^{11}$. Additionally, there are still limited and conflicting data for some antihistamine agents regarding increasing dose in children. In severe cases, corticosteroids such as prednisolone ( 0.5 to $1 \mathrm{mg}$ per $\mathrm{kg}$ per day) may be added for three to 10 days to control symptoms.

It is important to monitor for subsequent recurrence of urticaria, as almost third of our patients had recurrent rashes, with no effect from the first line of treatment. They may be in a risk group for developing chronic urticaria. However, it was a limitation of our observation, especially taking in the account current Covid-19 pandemic situation.

Our study confirms that the issues of diagnosis and rational management and treatment of acute urticaria in children should be unified and justified. Clearly identified indications for hospitalization and adequate treatment are designed to ensure principles of good clinical practice and reduce the cost of treatment of 
patients with $\mathrm{AU}$ and hospital resources using.

Further multicentral studies are required to investigate the rate of AU becoming chronic and how they link to the different causes in children with $\mathrm{AU}$ as well as to determine prognostic factors of recurrent urticaria in children.

N. Banadyha ${ }^{1}$, A. Nakonechna ${ }^{2}$

1- I. Horbachevsky Ternopil National Medical University, Ternopil, Ukraine

2- University of Liverpool, Department of Allergy, Clinical Immunology Royal Preston Hospital, Liverpool, United Kingdom

E-mails: natalia-fpo@tdmu.edu.ua;allanak1@yahoo.com

Conflict of interest: the authors declare that there is no conflict of interest.

Key words: children; acute urticaria; treatment.

References

1.Marques-Mejías M, Tomás-Pérez M, Vilà-Nadal G, et al. Acute urticaria in the pediatric emergency department. Annals of Allergy, Asthma \& Immunology 2020;124(4 ):396-397.

2. Talarico V, Marseglia GL, Lanari M,et al. Pediatric urticaria in the Emergency Department: epidemiological characteristics and predictive factors for its persistence in children. Eur Ann Allergy Clin Immunol 2020;1764-1489.148.

3.PierJ,BingemannTA. Urticaria, Angioedema, and Anaphylaxis. Pediatr Rev 2020;41(6):283-292.

4. Bernstein JA, Lang DM, Khan DA, et al. The diagnosis and management of acute and chronic urticaria:2014 update. J Allergy Clin Immunol 2014;133(5):1270-1277.

5. Powell RJ, Leech SC, Till S, et al. BSACI guideline for the management of chronic urticaria and angioedema. Clin.Exp Allergy 2015;45(3):547-565.

6.Ben-ShoshanM,GrattanCE. Management of Pediatric Urticaria with Review of the Literature on Chronic Spontaneous Urticaria in Children. J Allergy Clin Immunol Pract 2018;6(4):1152-1161.

7.ImbalzanoE,Casciaro M,QuartuccioS, et al. Association between urticaria and virus infections: A systematic review. Allergy Asthma Proc 2016;37(1):18-22.

8. Tang N,MaoMY,ZhaiR, et al.Clinical characteristics of urticaria in children versus adults. Zhongguo Dang Dai Er Ke Za Zhi 2017;19(7):790-795.

9.Minasi $\mathrm{D}$, MantiS, ChieraF, et al. Acute urticaria in the infant. Pediatric Allergy and Immunology 2020;31(S26):49-51.

10. Schaefer P. Acute and Chronic Urticaria: Evaluation and Treatment. American Family Physician 2017;95(11):717-724.

11. Food and Drug Administration (FDA).https://www.fda.gov/drugs. Accessed Dec 2019.

Table 1 Symptoms presentation and their duration 


\begin{tabular}{|c|c|c|c|c|c|c|c|c|c|c|c|}
\hline $\begin{array}{l}\text { Time } \\
\text { since } \\
\text { symp- } \\
\text { toms } \\
\text { oc- } \\
\text { curred }\end{array}$ & \multicolumn{2}{|c|}{\begin{tabular}{ll}
\multicolumn{2}{|c}{ AdmissioAdmissio } \\
to the & to the \\
hospi- & hospi- \\
tal & tal \\
$(\mathrm{n}=74)$ & $(\mathrm{n}=74)$ \\
\end{tabular}} & $\begin{array}{l}\text { on } \\
\text { Duratiol } \\
\text { of ur- } \\
\text { ticaria } \\
(n=74)\end{array}$ & $\begin{array}{l}\text { nDuratio } \\
\text { of ur- } \\
\text { ticaria } \\
(n=74)\end{array}$ & \multicolumn{2}{|c|}{$\begin{array}{l}\text { nDurationDuration } \\
\text { of an- of an- } \\
\text { gioedemagioedem } \\
(n=19) \quad(n=19)\end{array}$} & \multicolumn{5}{|c|}{ 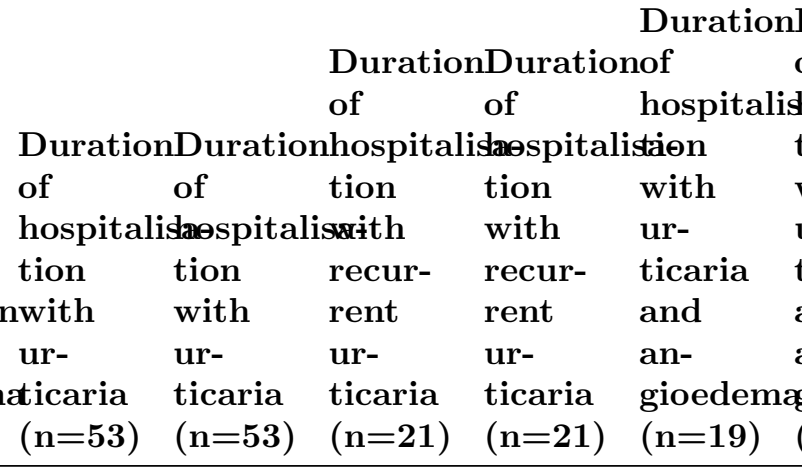 } \\
\hline & Abs. & $\%$ & Abs. & $\%$ & Abs. & $\%$ & Abs. & $\%$ & Abs. & $\%$ & Abs. \\
\hline $\begin{array}{l}\text { First } \\
\text { hours }\end{array}$ & 19 & 25.7 & - & - & - & - & - & - & - & - & - \\
\hline $\begin{array}{l}\text { 1st } \\
\text { day }\end{array}$ & 19 & 25.7 & 27 & 36.5 & 8 & 42.1 & 9 & 17.0 & - & - & 2 \\
\hline $\begin{array}{l}\text { 2nd } \\
\text { day }\end{array}$ & 9 & 12.2 & 15 & 20.3 & 5 & 26.3 & 6 & 11.4 & 1 & 4.8 & 1 \\
\hline $\begin{array}{l}\text { 3rd } \\
\text { day }\end{array}$ & 10 & 13.5 & 11 & 14.9 & 2 & 10.5 & 7 & 13.2 & 1 & 4.8 & 1 \\
\hline $\begin{array}{l}\text { 4th } \\
\text { day }\end{array}$ & - & - & 6 & 8.1 & 3 & 15.8 & 5 & 9.4 & 1 & 4.8 & 3 \\
\hline $\begin{array}{l}5 \text { th } \\
\text { day }\end{array}$ & - & - & 5 & 6.8 & 1 & 5.3 & 7 & 13.2 & 2 & 9.6 & 2 \\
\hline $\begin{array}{l}\text { 6th } \\
\text { day }\end{array}$ & - & - & 3 & 4.0 & - & - & 9 & 17.0 & 7 & 33.3 & 2 \\
\hline $\begin{array}{l}\text { 7th } \\
\text { day }\end{array}$ & 13 & 17.5 & 3 & 4.0 & - & - & 5 & 9.4 & 3 & 14.2 & 3 \\
\hline $\begin{array}{l}\text { ¿7 } \\
\text { days }\end{array}$ & 4 & 5.4 & 4 & 5.4 & - & - & 5 & 9.4 & 6 & 28.5 & 5 \\
\hline
\end{tabular}

\section{Hosted file}

table.pdf available at https://authorea.com/users/404974/articles/516053-acute-urticaria-inchildren-what-can-we-learn-from-clinical-practice 